\section{(B) OPEN ACCESS}

\title{
Loss of function of the E3 ubiquitin-protein ligase UBE3B causes Kaufman oculocerebrofacial syndrome
}

\author{
Elisabetta Flex, ${ }^{1}$ Andrea Ciolfi, ${ }^{1,2}$ Viviana Caputo, ${ }^{3}$ Valentina Fodale, ${ }^{1}$ Chiara Leoni, ${ }^{4}$ \\ Daniela Melis, ${ }^{5}$ Maria Francesca Bedeschi, ${ }^{6}$ Laura Mazzanti, ${ }^{7}$ Antonio Pizzuti, ${ }^{3}$ \\ Marco Tartaglia, ${ }^{1}$ Giuseppe Zampino ${ }^{4}$
}

- Additional material is published online only. To view please visit the journal online (http://dx.doi.org/10.1136/ jmedgenet-2012-101405)

${ }^{1}$ Dipartimento di Ematologia, Oncologia e Medicina Molecolare, Istituto Superiore di Sanità, Rome, Italy ${ }^{2}$ Dipartimento di Medicina Molecolare, Università "La Sapienza", Rome, Italy ${ }^{3}$ Dipartimento di Medicina Sperimentale, Università "La Sapienza", Rome, Italy ${ }^{4}$ Dipartimento di Scienze Pediatriche, Università Cattolica del Sacro Cuore, Rome, Italy ${ }^{5}$ Dipartimento di Pediatria, Facoltà di Medicina e Chirurgia, Università "Federico II", Naples, Italy ${ }^{6}$ UOD Genetica Medica, Fondazione IRCCS Ca' Granda Ospedale Maggiore Policlinico, Milan, Italy

${ }^{7}$ Dipartimento di Pediatria, Università degli Studi di Bologna, Bologna, Italy

\section{Correspondence to} Dr Marco Tartaglia, Dipartimento di Ematologia, Oncologia e Medicina Molecolare, Istituto Superiore di Sanità, Viale Regina Elena, 299, Rome 00161, Italy; mtartaglia@iss.it

MT and GZ contributed equally.

Received 7 November 2012 Revised 3 April 2013 Accepted 18 April 2013 Published Online First 17 May 2013

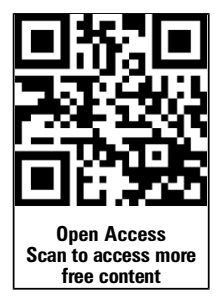

To cite: Flex E, Ciolfi A, Caputo V, et al. J Med Genet 2013;50:493-499.

\section{ABSTRACT}

Background Kaufman oculocerebrofacial syndrome

(KOS) is a developmental disorder characterised by reduced growth, microcephaly, ocular anomalies (microcornea, strabismus, myopia, and pale optic disk), distinctive facial features (narrow palpebral fissures, telecanthus, sparse and laterally broad eyebrows, preauricular tags, and micrognathia), mental retardation, and generalised hypotonia. KOS is a rare, possibly underestimated condition, with fewer than 10 cases reported to date. Here we investigate the molecular cause underlying KOS.

Methods An exome sequencing approach was used on a single affected individual of an Italian consanguineous family coupled with mutation scanning using Sanger sequencing on a second unrelated subject with clinical features fitting the disorder.

Results Exome sequencing was able to identify homozygosity for a novel truncating mutation (c.556C >T, p.Arg186stop) in UBE3B, which encodes a widely expressed HECT (homologous to the E6-

AP carboxyl terminus) domain E3 ubiquitin-protein ligase. Homozygosity for a different nonsense lesion affecting the gene (c.1166G >A, p.Trp389stop) was documented in the second affected subject, supporting the recessive mode of inheritance of the disorder. Mutation scanning of the entire UBE3B coding sequence on a selected cohort of subjects with features overlapping, in part, those recurring in KOS did not reveal disease-causing mutations, suggesting phenotypic homogeneity of UBE3B lesions.

Discussion Our data provide evidence that KOS is caused by UBE3B loss of function, and further demonstrate the impact of misregulation of protein ubiquitination on development and growth. The available clinical records, including those referring to four UBE3B mutation-positive subjects recently described as belonging to a previously unreported entity, which fits KOS, document the clinical homogeneity of this disorder.

\section{INTRODUCTION}

Kaufman oculocerebrofacial syndrome (KOS) (MIM 244450) is the eponym for the disorder originally described by Kaufman, Rimoin and co-workers 40 years ago in four of seven sibs born to unaffected parents exhibiting mental retardation, microcephaly, upward palpebral fissures, microcornea, severe myopia, optic atrophy, preauricular skin tags, high arched palate, and micrognathia. ${ }^{1} \mathrm{KOS}$ is an extremely rare, possibly underestimated condition, with fewer than 10 affected individuals reported to date. ${ }^{2-4}$ Based on the available records, main features include microbrachycephaly, distinctive face, eye anomalies (small cornea, strabismus, myopia, and pale optic disk), mild to severe psychomotor retardation, hypotonia, delayed growth, and skeletal features (bell shaped thorax with telethelia, long and thin fingers). The recognisable facial appearance is characterised by sparse and laterally broad eyebrows, upslanting and narrow palpebral fissures, telecanthus, anteverted nostrils with columella below alae nasi, and micrognathia. Small, poorly formed and frail teeth and a high, narrow palate have commonly been reported.

A recurrent feature of KOS is the presence of anomalies of structures that are derived from the first and second pharyngeal arches, since external ear anomalies (cup shaped ears and stenotic auditory canal) and preauricular tags have been described to occur concomitantly with micrognathia in affected subjects. The presence of blepharophimosis and mental retardation, with or without microcephaly and micrognathia, is described in a heterogeneous group of multiple congenital malformation disorders, including Dubowitz syndrome (MIM 223370), MardenWalker syndrome (MIM 248700), Smith-LemliOpitz syndrome (MIM 270400), and Ohdo syndrome (MIM 249620) and related phenotypes. ${ }^{5}$ In those conditions, however, individual combinations of congenital anomalies, facial gestalt, and natural history are definitely different from the constellation of features occurring in KOS. Here, an exome sequencing approach was employed to identify UBE3B (MIM 608047), which encodes an E3 ubiquitin-protein ligase, as the gene mutated in $\mathrm{KOS}$, confirming this disorder as a distinct nosologic entity inherited as an autosomal recessive trait.

\section{SUBJECTS AND METHODS \\ Patients and families}

Two unrelated individuals with clinical features fitting KOS were included in the study (figure $1 \mathrm{~A}$, see online supplementary table S1). In the subjects, karyotype and subtelomeric fluorescence in situ hybridisation (FISH) analyses were normal. Similarly, high resolution array comparative genomic hybridisation analysis did not disclose any disease-causing genomic rearrangement in either proband. Twelve subjects who had no confirmed clinical diagnosis and sharing features overlapping, 


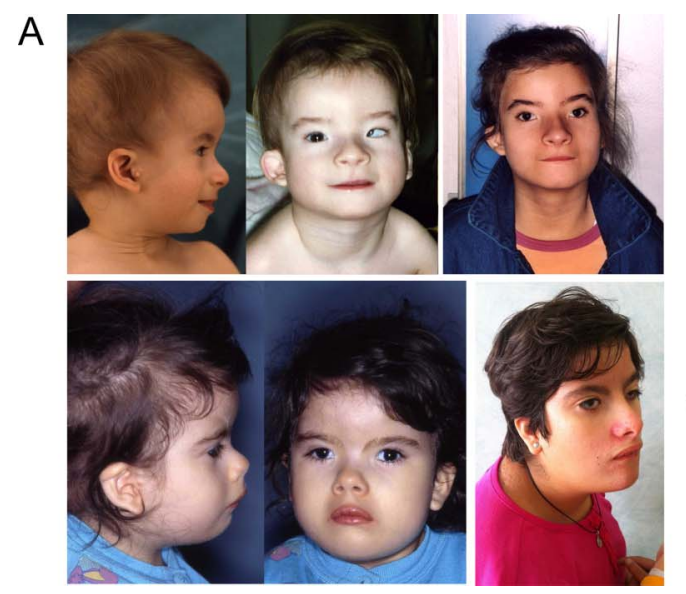

B
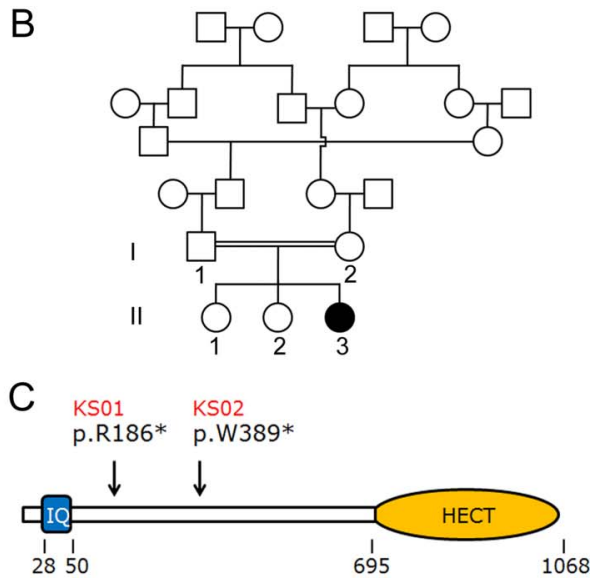

Figure 1 Craniofacial features in Kaufman oculocerebrofacial syndrome and UBE3B domain structure. (A) The recognisable facial gestalt of the two affected subjects (UCSC_KS01, above; UCSC_KSO2, below). Note the distinctive facies of the two affected subjects with microcephaly, sparse eyebrows with unusual profile, upslanting and narrow palpebral fissures, strabismus, cup shaped ears, preauricular tags, and micrognathia. (B) Pedigree structure of family UCSC_KS01. Genotyped members are indicated. (C) Scheme of the UBE3B domain structure. The ubiquitin ligase comprises an N-terminal IQ domain (IQ), and a $C$-terminal catalytic domain (homologous to the E6-AP carboxyl terminus). Numbers below the diagram indicate the amino acid boundaries of those domains. The location of identified mutations in patients UCSC_KSO1 and UCSC_KSO2 is also reported.

in part, those recurring in KOS, together with the patient originally reported by Briscioli et al, ${ }^{6}$ were all included for mutation scanning of the UBE3B gene (see online supplementary table S2). For all patients, clinical data and biological material collection and storage were obtained from the participating families after they provided written informed consent.

\section{Exome sequencing and sequence data analysis}

Targeted enrichment and massively parallel sequencing were performed on genomic DNA extracted from circulating leucocytes of patient UCSC-KS01. Exome capture was performed using NimbleGen SeqCap EZ Exome V. 2.0 (Roche), and sequencing using a HiSeq2000 instrument (Illumina). Paired-end reads were aligned to human genome (UCSC GRCh37/hg19) with the Burrows-Wheeler Aligner (BWA V. 0.5.9-rc1). ${ }^{7}$ Presumed PCR duplicates were discarded with the Picard's MarkDuplicates utility (http://picard.sourceforge.net). Local realignment and base-quality-score recalibration were performed with the Genome Analysis Toolkit (GATK). ${ }^{8}$ Single nucleotide polymorphisms (SNPs) and indels were identified with the GATK Unified Genotyper, ${ }^{9}$ excluding from further analyses variants which failed to meet any of the following criteria: alignment quality $>50$; quality-by-depth score $>1.5$; variant resulting from $>3$ reads having unambiguous mapping (the number being $>1$ / 10 of all aligned reads). Variants were filtered against available public (1000 Genomes Project and dbSNP135) and in-house databases. Functional annotation of variants was performed by using snpEff V. 2.0.5 d. ${ }^{10}$ Variants within segmental duplications and variants outside highly conserved regions in vertebrates were filtered using wAnnovar (http://wannovar.usc.edu).

\section{Variant validation and mutation analysis}

Sequence validation and segregation analyses for all the candidate variants as well as mutation scanning of the entire $U B E 3 B$ coding sequence (exons 1-26) (NM_130466) was performed by Sanger sequencing using an ABI Prism 3500 Genetic Analyzers (Applied Biosystems) and the ABI BigDye Terminator Sequencing Kit V.3.1 (Applied Biosystems). Primer pairs designed to amplify the $U B E 3 B$ coding exons and their intron boundaries are listed in online supplementary table S3.
Sequence comparisons and analyses were performed using the Sequencing Analysis Software V.5.4 (Applied Biosystems).

\section{RESULTS}

Exome sequencing obtained of 52 million 90 bp paired-end reads. Following the alignment pipeline, target region coverage was $99.2 \%$, with average sequencing depth on target of $56 \times$. The total number of variants called was 33657 (32111 SNPs and 1546 small INDELS (insertions and deletions)). Among them, 32012 are annotated in dbSNP135. The remaining 1645 variants were filtered to retain 323 sequence changes located in exons and splice sites with any functional effect, which were selected for further analyses. Variants annotated in the 1000 Genomes Project variant and in-house databases were also removed, leading to a total of 152 previously unreported variants.

Since there was evidence of consanguinity in the family (figure 1B), we considered homozygosity for a private variant as the most likely event underlying the trait. Autosomal recessive pattern of inheritance was also consistent with the multiple occurrences in sibs of both sexes with unaffected parents in the originally reported family. ${ }^{1}$ According to a recessive model, a list of 11 variants in eight candidate genes was compiled. Based on the hypothesis of homozygosity by descent, the list of candidates was reduced to five genes (PLD1, NDUFB9, PTCHD3, UBE3B, and $V W A 3 B)$. Given the relevance of ubiquitination mediated processes in development and morphogenesis, and the dramatic functional impact of the sequence change (c.556C $>\mathrm{T}$, p.Arg186stop), we considered $U B E 3 B$ as the most promising disease gene candidate. $U B E 3 B$ encodes a member of the 'homologous to E6-AP carboxyl terminus' domain containing E3 ubiquitin-protein ligase enzyme family. ${ }^{11}$ The protein is characterised by an IQ domain near to the $N$-terminus (residues 28 to 50), which mediates protein binding, and a HETC domain at the C-terminus (residues 695-1068) (http://smart.embl-heidelberg. $\mathrm{de} /$ ) (figure 1C). As the latter represents the catalytic site, interacting with the $\mathrm{E} 2$ conjugase and mediating ubiquitin transfer to the protein substrate, the nonsense mutation was predicted to result in a catalytically impaired protein.

Sanger sequencing of the relevant coding exon confirmed the homozygous condition for the c.556C $>\mathrm{T}$ nucleotide 
substitution in the affected subject (figure 2A), and excluded homozygosity for the lesion in the two unaffected sibs. Occurrence of the nucleotide change was also excluded in 400 population matched control subjects. Consistent with the view that this nonsense change in $U B E 3 B$ was the causative mutation, the other two of the five unannotated homozygous variants confirmed by Sanger sequencing were documented to occur as homozygous changes also in one of the two unaffected sibs, excluding their causal link with the disease. Similarly, segregation analysis of validated variant pairs identified in the BRD8, IQGAP2, and SYNE2 genes excluded the occurrence of compound heterozygosity for mutations in each of these genes as disease-causing events. No functionally relevant sequence variation in the coding sequence and flanking intronic regions of DHCR7 (MIM 602858) and KAT6B (MIM 605880), which are mutated respectively in Smith-Lemli-Opitz and Ohdo syndromes, was identified $(27 \times$, mean depth coverage). Overall, these findings strongly pointed to $U B E 3 B$ as the gene mutated in KOS.

To confirm the causal involvement of $U B E 3 B$ in the disorder, the entire coding sequence of the gene was scanned for mutations in DNA obtained from circulating leucocytes from a second, unrelated subject with clinical features fitting the trait (UCSC-KS02), whose apparently non-consanguineous family originated from a small (400 inhabitants), possibly endogamous village of southern Italy. Mutation analysis permitted the identification of a different homozygous nonsense lesion, c.1166G $>$ A, predicting premature termination of the protein at codon 389 (p.Trp389stop) (figure 2A). Genotyping of parental DNAs demonstrated the heterozygous conditions for the truncating lesion, while the nucleotide substitution was not observed to occur in public databases as well as in the control DNA group (see above) scanned by high resolution melting analysis and direct sequencing. Similar to what was observed for the truncating c.556C $>\mathrm{T}$ change, the nonsense nucleotide substitution affected a region that was located upstream of the catalytic domain, thus leading to loss of UBE3B's ubiquitin ligase function in the patient.

To assess more precisely the phenotypic variability associated with mutations of $U B E 3 B$, scanning of the entire coding sequence of the gene was performed on a selected cohort of subjects with features overlapping, in part, those recurring in KOS (see online supplementary table S2). These subjects exhibited a unique combination of features recurring in KOS, and none of them showed a phenotype fitting Ohdo syndrome or any other disorder considered in the differential diagnosis of KOS. Mutation analysis was also performed on the patient originally described by Briscioli et $a l^{6}{ }^{6}$ for whom a diagnosis of KOS was proposed on the basis of co-occurrence of cognitive deficits, suggestive facial features (microcephaly, long and narrow face, sparse eyebrows, upslanting palpebral fissures, abnormal columella, and unusual nasal configuration), ocular anomalies, long and thin hands and feet, together with neonatal respiratory difficulties. The phenotype, however, was distinctive for the lack of blepharophimosis, reduced corneal diameter, ear anomalies, micrognathia, and significant neonatal feeding problems (see online supplementary table S2). No disease-causing mutation was identified in this group of patients, suggesting that $U B E 3 B$ lesions were likely to be associated with a relatively homogeneous phenotype.

While this work was under review, biallelic mutations in $U B E 3 B$ were reported by Basel-Vanagaite $e t a l^{12}$ in four subjects from three unrelated families who were described as presenting a previously unrecognised, autosomal recessive entity characterised by blepharophimosis, facial dysmorphism, microcephaly, cognitive deficits, and reduced growth. Consistent with the present findings, three of the four reported $U B E 3 B$ mutations were truncating (figure 2B), supporting the idea of UBE3B loss of function as the shared molecular event underlying their
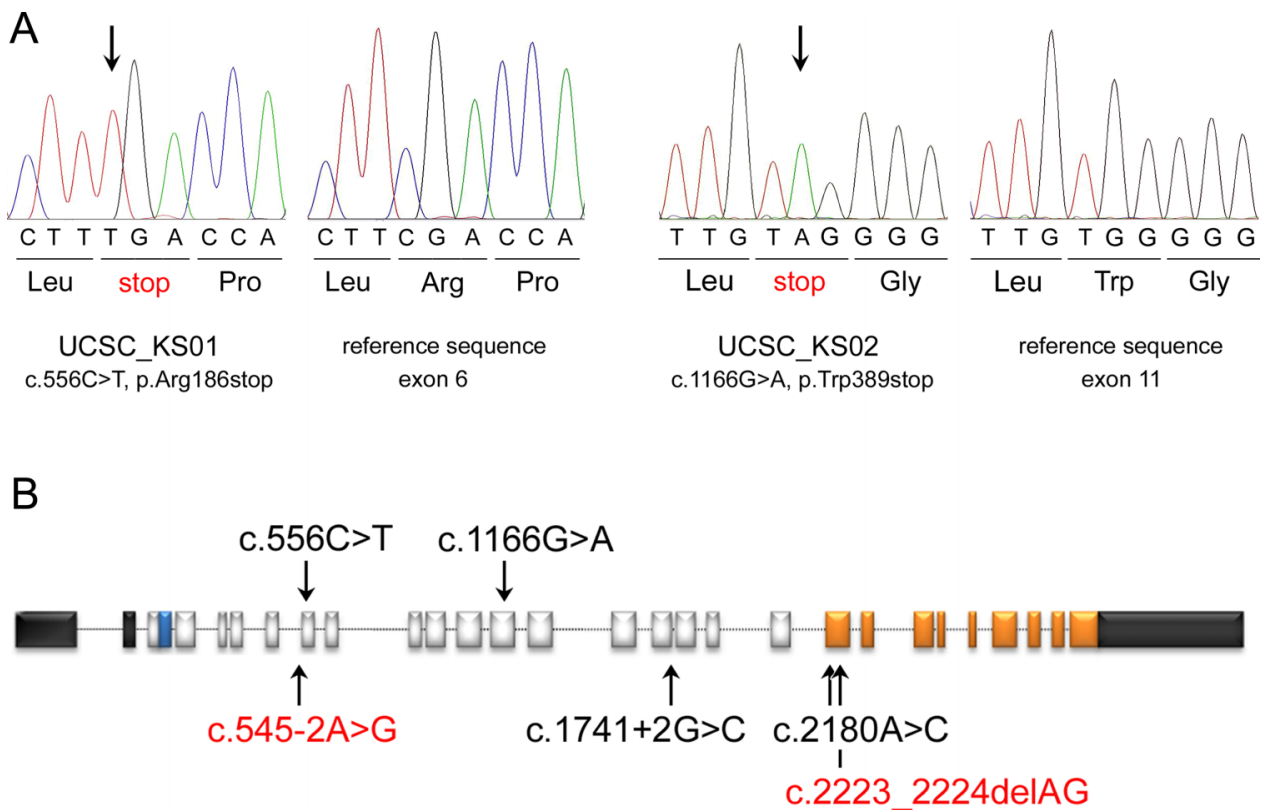

Figure 2 Truncating and missense mutations in UBE3B cause Kaufman oculocerebrofacial syndrome. (A) Chromatograms documenting homozygosity for the nonsense mutations identified in the two affected individuals included in this study are reported together with the respective reference sequences. (B) Location of disease causative mutations. The UBE3B gene includes 26 coding exons. The $5^{\prime}$ - and $3^{\prime}$-untranslated regions are shown in black. Exonic regions coding for the IQ motif and the HECT domain are reported in blue and orange, respectively. The mutations identified in the present study are shown above the diagram, while those reported by Basel-Vanagaite et $a^{12}$ are listed below. Homozygosity was documented in four unrelated subjects (black), while compound heterozygosity was reported in two siblings (red). 
phenotype. Extensive clinical information was available for the six UBE3B mutation-positive patients (table 1). Overall, these subjects presented with a remarkably homogeneous phenotype that undoubtedly fits the condition originally described by Kaufman et al. ${ }^{1-4}$ From the analysis of the published and present records, the recognisable craniofacial appearance of KOS is characterised by microbrachycephaly, narrow and upward oriented palpebral fissures, epicanthus, telecanthus, a distinctive pattern of the eyebrows that originate under the orbital arch and are directed upward, becoming wide and sparse

Table 1 Clinical presentation of subjects with biallelic inactivating UBE3B gene mutations

\begin{tabular}{|c|c|c|c|c|c|c|c|}
\hline $\begin{array}{l}\text { Subject(s) } \\
\text { Reference(s) }\end{array}$ & UCSC-KS01 & UCSC-KS02 & $\begin{array}{l}1 \\
12\end{array}$ & $\begin{array}{l}2-1 \\
12\end{array}$ & $\begin{array}{l}2-2 \\
12\end{array}$ & $\begin{array}{l}3 \\
12\end{array}$ & $\begin{array}{l}\text { KOS } \\
1-4\end{array}$ \\
\hline UBE3B mutations & $\begin{array}{l}\text { c. } 556 \mathrm{C}>\mathrm{T}^{*} \\
\text { truncating }\end{array}$ & $\begin{array}{l}\text { c. } 1166 \mathrm{G}>\mathrm{A}^{*} \\
\text { truncating }\end{array}$ & $\begin{array}{l}\text { c. } 1741+2 \mathrm{G}>\mathrm{C}^{*} \\
\text { truncating }\end{array}$ & \multicolumn{2}{|c|}{$\begin{array}{l}\text { c.545-2A>G } \\
\text { truncating } \\
\text { c.2223_2224delAG } \\
\text { truncating }\end{array}$} & $\begin{array}{l}\text { c. } 2180 A>C^{*} \\
\text { p.Q727P }\end{array}$ & Unknown \\
\hline Sporadic/familial & Sporadic & Sporadic & Sporadic & Familial & & Sporadic & $\begin{array}{l}1 \text { familial } \\
4 \text { sporadic }\end{array}$ \\
\hline Sex & Female & Female & Female & Female & Male & Female & $\begin{array}{l}5 \text { female } \\
3 \text { male }\end{array}$ \\
\hline \multicolumn{8}{|l|}{ Neonatal findings } \\
\hline Weight & 25th cent. & 3rd cent. & 3rd cent. & 3rd cent. & 3rd cent. & $\mathrm{nr}$ & Variablet \\
\hline Respiratory distress & + & + & + & + & - & + & $+(7 / 7)$ \\
\hline Laryngeal stridor/noisy breathing & + & + & + & - & - & + & $+(3 / 4)$ \\
\hline Failure to thrive & + & + & + & + & + & + & $+(5 / 6)$ \\
\hline Feeding difficulties & + & + & + & + & + & + & $+(5 / 6)$ \\
\hline Reduced growth & + & + & - & + & + & + & $+(3 / 7)$ \\
\hline Delayed psychomotor development & + & + & + & + & + & + & $+(8 / 8)$ \\
\hline Delayed language & + & + & + & + & + & + & $+(4 / 4)$ \\
\hline Seizures & + & + & - & - & - & + & $-(1)$ \\
\hline Shuffling gait & + & + & $\mathrm{nr}$ & $\mathrm{nr}$ & $\mathrm{nr}$ & & $+(3 / 4)$ \\
\hline Hypotonia & + & + & + & + & - & + & $+(5 / 6)$ \\
\hline \multicolumn{8}{|l|}{ Craniofacial features } \\
\hline Microbrachycephaly & + & + & + & + & + & + & $+(7 / 7)$ \\
\hline Long face & + & - & - & + & + & + & $+(5 / 7)$ \\
\hline Sparse and laterally broad eyebrows & + & + & + & + & + & + & $+(7 / 7)$ \\
\hline Upslanting palpebral fissures & + & + & - & + & + & - & $+(7 / 7)$ \\
\hline Telecanthus & + & + & + & + & + & + & $+(5 / 6)$ \\
\hline Blepharophimosis & + & + & + & + & + & + & $+(3 / 4)$ \\
\hline Ptosis & - & + & + & $+\ddagger$ & - & + & $+(2 / 3)$ \\
\hline Epicanthal folds & + & + & + & + & + & + & $+(4 / 7)$ \\
\hline Short nose & + & + & + & + & + & + & $+(2 / 3)$ \\
\hline Anteverted nares/columella below alae nasi & + & + & + & + & + & + & $+(2 / 3)$ \\
\hline Long philtrum & + & + & + & + & + & + & $+(5 / 6)$ \\
\hline Thin lips & + & - & - & + & + & + & $+(7 / 7)$ \\
\hline Small mouth & + & + & + & + & + & + & $+(3 / 5)$ \\
\hline Micrognathia & + & + & + & + & + & + & $+(8 / 8)$ \\
\hline High, narrow palate & $+\S$ & + & + & $+\S$ & - & - & $+(5 / 5)$ \\
\hline Small/frail teeth & + & + & - & - & - & $\mathrm{nr}$ & $+(6 / 7)$ \\
\hline Cup shaped ears & + & + & + & + & + & + & $+(7 / 8)$ \\
\hline Preauricular tags & + & + & - & - & - & - & $+(1 / 8)$ \\
\hline Auricular stenosis & + & + & - & - & - & - & $\mathrm{nr}$ \\
\hline \multicolumn{8}{|l|}{ Eye anomalies } \\
\hline Microcornea & +9 & +9 & $\mathrm{nr}$ & $\mathrm{nr}$ & $\mathrm{nr}$ & $\mathrm{nr}$ & $+(5 / 7)$ \\
\hline Strabismus & + & + & - & + & - & - & $+(6 / 7)$ \\
\hline Pale disk & + & + & - & - & - & - & $-(5 / 7)$ \\
\hline Nystagmus & - & - & - & - & - & - & $-(1 / 6)$ \\
\hline Myopia/astigmatism & + & - & - & + & - & - & $+(5 / 6)$ \\
\hline Hearing impairment & + & + & + & - & - & - & $\mathrm{nr}$ \\
\hline \multicolumn{8}{|l|}{ Skeletal features } \\
\hline Bell shaped thorax & + & + & $\mathrm{nr}$ & $\mathrm{nr}$ & $\mathrm{nr}$ & $\mathrm{nr}$ & $+(5 / 6)$ \\
\hline Long and thin fingers & + & + & $\mathrm{nr}$ & $\mathrm{nr}$ & $\mathrm{nr}$ & $\mathrm{nr}$ & $+(6 / 6)$ \\
\hline Coxa valga & + & - & $\mathrm{nr}$ & $\mathrm{nr}$ & $\mathrm{nr}$ & $\mathrm{nr}$ & $+(2 / 2)$ \\
\hline Pes talus valgus/varus & + & + & $\mathrm{nr}$ & $\mathrm{nr}$ & $\mathrm{nr}$ & $\mathrm{nr}$ & $+(2 / 3)$ \\
\hline
\end{tabular}


Table 1 Continued

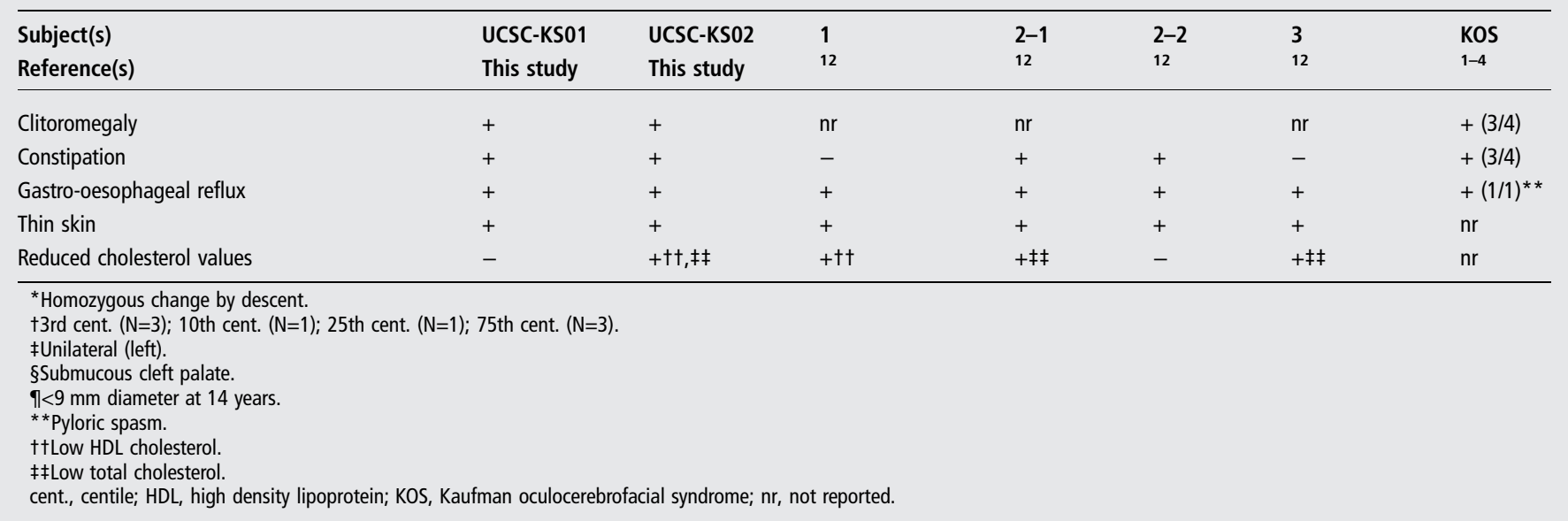

especially in the third lateral, small nose with anteverted nostrils, long philtrum, thin lips, and small mouth.

Micrognathia is a constant feature, and usually associated with a high, narrow or cleft palate. The teeth are small, poorly formed, frail, and with multiple caries. Ear features include a cup shape with hypoplastic lobe and folded helix, stenosis of the external meatus, and preauricular tags. Microcornea, strabismus, myopia, and pale optic disk are frequently observed; nystagmus may also occur. A bell shaped thorax with telethelia is commonly observed, and fingers are generally long and thin with hyperextensibility at the metacarpophalangeal joints. The lower limbs are frequently involved with coxa valga and metatarsus varus in both feet. The natural history of KOS also appears rather constant, particularly during the neonatal period, with respiratory distress and laryngeal stridor, and growth retardation-the latter mainly ascribed to feeding difficulties due to poor sucking, pylorospasm and gastro-oesophageal reflux. Delayed psychomotor/language development and moderate to severe cognitive deficits are almost invariably observed; hypotonia is common. The gait is clumsy, crawling with widened basis but without signs of ataxia. Febrile seizures may occur without a significant electroencephalogram pattern. Affected subjects generally present a very similar behaviour with sociable and good natured disposition. Consistent with the observation of hypocholesterolaemia in three of the four $U B E 3 B$ mutation-positive subjects reported by Basel-Vanagaite et $a l,{ }^{12}$ low concentrations of total/high density lipoprotein cholesterol were documented in patient UCSC_KS02, confirming an underlying defect in cholesterol metabolism possibly resulting in decreased cholesterol synthesis. ${ }^{12}$

\section{DISCUSSION}

We report here that UBE3B loss of function underlies KOS. UBE3B is a still functionally uncharacterised E3 ubiquitinprotein ligase. It is widely expressed during development as well as in adult tissues. Specifically, UBE3B has been reported to be highly expressed in the central nervous system (eg, cerebral cortex and cerebellum), digestive tract (eg, oesophagus and stomach), respiratory system (eg, nasopharynx and bronchi), as well as in multiple cell lineage of skin and other soft tissues (fibroblasts, chondrocytes, and epithelial cells) (http://www. proteinatlas.org/ENSG00000151148/; http://www.ebi.ac.uk/ $\mathrm{gxa} /)^{12}$. While the functional characterisation of the E3 ligase properties of UBE3B in terms of substrate specificity and cellular pathways is required to appreciate the molecular mechanism(s) implicated in perturbation of the developmental processes promoted by impaired UBE3B function, mutation data indicate that the disease-causing lesions selectively interfere with the catalytic function of the protein. Among the six reported disease-associated mutations, five different nonsense, frameshift, and splice site mutations are predicted to cause protein truncation before or at the beginning of the HECT domain (figure 2B), and consequently to abolish UBE3B's E3 ligase activity. Consistent with this finding, $U b e 3 b^{-/-}$mice exhibit a severely reduced bodyweight and size, decreased growth rate, muscular hypotonia, mild hearing impairment, and a reduced total cholesterol value, recapitulating several key features of KOS. ${ }^{12}$ Of note, human $U B E 3 B$ encodes multiple gene products, which result from alternative transcript processing. Among these, two mRNA species contain alternative $3^{\prime}$ coding exons, resulting in products with a distinct, truncated $C$-terminus lacking the HETC domain. One of these truncated isoforms has been hypothesised to retain its ability to bind to substrates and possibly work as a negative regulator of UBE3B's ubiquitin ligase function. ${ }^{11}$ While alternative splicing in $U B E 3 B$ has been proposed to possibly represent a novel fine-tuning mechanism in regulating activities of HECT domain ligases, the present observation that heterozygosity for a catalytically impaired UBE3B mutant does not result in any noticeable clinical phenotype and apparently does not operate with a dominant negative effect is contrary to this idea.

Analysis of the available clinical records supports the view that biallelic inactivation of UBE3B underlies the oculocerebrofacial syndrome originally recognised by Kaufman et al. ${ }^{1}$ While further investigations are required to define more precisely the molecular diversity of disease-causing mutations as well as the clinical spectrum associated with $U B E 3 B$ mutations, screening of the entire coding sequence of the gene in a clinically heterogeneous cohort of patients sharing, in part, clinical features with KOS did not reveal any mutations. This finding suggests that loss of UBE3B catalytic function is associated with a clinically complex but relatively homogeneous and recognisable disorder in which anomalies involving the central nervous system (developmental delay, cognitive deficits, and hypotonia), cranium and face (microcephaly, distinctive eyebrow pattern, blepharophimosis, telecanthus, small nose with anteverted nostrils, long philtrum and small mouth), eyes (small cornea/microcornea, strabismus, myopia and pale optic disk), derivatives of the first and second pharyngeal arches (micrognathia, high and narrow/ cleft palate, auricular stenosis, and preauricular tags), and other 
functional issues (neonatal respiratory difficulties, feeding and gastrointestinal problems and postural anomalies) co-occur as cardinal features. This conclusion is further supported by the data reported in the literature by Basel-Vanagaite et al, ${ }^{12}$ published while this work was under revision, which allows KOS to be defined clinically more precisely.

Ubiquitination is a widely used post-translational process employed to tag proteins for their degradation or intracellular sorting, as well as to modify their function directly. ${ }^{13}{ }^{14}$ This protein modification has emerged as a critical mechanism involved in the regulation of a wide array of cellular processes, including cell division and differentiation, as well as development, with as many as $30-40 \%$ of all proteins estimated to be ubiquitinated in mammalian cells. ${ }^{15}$ Ubiquitination involves three classes of enzymes (E1 ubiquitin-activating enzymes, E2 ubiquitin-conjugating enzymes and E3 ubiquitin-protein ligases) that are required to catalyse ubiquitin activation and assembly of ubiquitin monomers or chains onto substrates. Among these, the E3 ubiquitin ligases constitute the largest group, including several hundred enzymes of various classes. ${ }^{16}$ By coupling substrate binding and ubiquitin transfer, E3 enzymes control the efficiency and specificity of protein ubiquitination. Within this group, the HETC domain-containing E3 ligases constitute a modest sized family of proteins defined by a conserved $\mathrm{C}$-terminal catalytic domain and a variable $\mathrm{N}$-terminal region conferring the ability to bind specifically to their substrates. ${ }^{17}$ Defective function of this class of E3 ligase has been documented to affect development. Loss of function of UBE3A (MIM 601623) has been identified to underlie Angelman syndrome (MIM 105830), a neurodevelopmental disorder characterised by severe cognitive deficiency, speech impairments, epilepsy, distinctive ataxic movements, abnormal sleep patterns, and hyperactivity. ${ }^{18} 19$

Other E3 ligases have been implicated in the pathogenesis of human genetic diseases, including von Hippel-Lindau disease (MIM 193300) (VHL, MIM 608537), ${ }^{20}$ autosomal recessive juvenile Parkinson disease (MIM 600116) (PARK2, MIM 602544), ${ }^{21}$ 3M syndrome (MIM 273750) (CUL7, MIM 609577), ${ }^{22}$ Johanson-Blizzard syndrome (MIM 243800) (UBR1, MIM 605981), ${ }^{23}$ autoimmune polyendocrine syndrome type 1 (MIM 240300) (AIRE, MIM 607358), ${ }^{24}$ and the CBL (MIM 165360) mutation associated RASopathy (MIM 613563). ${ }^{25-27}$ The present findings provide further evidence of the dramatic impact of misregulation of protein ubiquitination on developmental processes. Notably, a key aspect of KOS is the involvement of structures that derive from the first and second pharyngeal arches. These embryonic domains, also known as branchial arches, are composed of mesenchymal cells of mesodermal and cranial neural crest origin, and give rise to a wide variety of skeletal, muscular, and neural elements of the face. ${ }^{28}$ Commitment, survival, migration, expansion, and differentiation of these cells is coordinated by a complex signalling network, whose deregulation has an impact on the development of many of the structures of the face. ${ }^{29} 30$ The abrogated function of UBE3B in KOS for the first time documents the relevant role of ubiquitination mediated processes in controlling developmental programmes of derivatives of these embryonic domains.

Acknowledgements We are indebted to the families who participated in the study and Serenella Venanzi (Istituto Superiore di Sanità, Rome, Italy) for experimental support. We thank BGI (Hong Kong) for the high quality raw sequencing data.

Contributors EF and VF performed biological sample processing, sequence data validation, segregation analyses, and mutation screening; $A C$ and VC performed the bioinformatics analyses of exome sequencing data; $C L, D M, M F B, L M, A P$ and $G Z$ recruited patients, collected biological samples, and performed clinical evaluations; EF, MT and GZ wrote the manuscript; MT and GZ conceived the study and analysed the data.

Funding Istituto Superiore di Sanità (ricerca corrente 2012) and Telethon-Italy (GGP10020) to M.T.

Competing interests None.

Patient consent Obtained.

Ethics approval Istituto Superiore di Sanita', Rome, Italy.

Provenance and peer review Not commissioned; externally peer reviewed.

Web resources Accession numbers and the URL for data are as follows: Online Mendelian Inheritance in Man (OMIM), http://www.omim.org dbSNP, http://www.ncbi.nlm.nih.gov/projects/SNP

1000 Genomes Project variant database, http://www.1000genomes.org/ wAnnovar, http://wannovar.usc.edu

Picard's MarkDuplicates utility, http://picard.sourceforge.net

Entrez Gene, http://www.ncbi.nlm.nih.gov/gene/

Simple Modular Architecture Research Tool (SMART), http://smart.embl-heidelberg.de/

Gene Expression Atlas, http://www.ebi.ac.uk/gxa/

Human Protein Atlas, http://www.proteinatlas.org/ENSG00000151148/.

Open Access This is an Open Access article distributed in accordance with the Creative Commons Attribution Non Commercial (CC BY-NC 3.0) license, which permits others to distribute, remix, adapt, build upon this work non-commercially, and license their derivative works on different terms, provided the original work is properly cited and the use is non-commercial. See: http://creativecommons.org/ licenses/by-nc/3.0/

\section{REFERENCES}

1 Kaufman R, Rimoin DL, Prensky AL, Sly WS. An oculocerebrofacial syndrome. Birth Defects Orig Art Ser 1971;7:135-8.

2 Jurenka SB, Evans J. Kaufman oculocerebrofacial syndrome: case report. Am J Med Genet 1979;3:15-19.

3 Garcia-Cruz D, Arreola R, Sanchez-Corona J, Garcia-Cruz O, Renteria R, Villar V, Gonzalez ME, Vargas-Moyeda E, Cantu JM. Kaufman oculocerebrofacial syndrome: a corroborative report. Dysmorph Clin Genet 1988;1:152-4.

4 Figuera LE, Garcia-Cruz D, Ramirez-Duenas ML, Rivera-Robles V, Cantu JM. Kaufman oculocerebrofacial syndrome: report of two new cases and further delineation. Clin Genet 1993:44:98-101.

5 Verloes A, Bremond-Grignac D, Isidor B, David A, Baumann C, Leroy MA, Stevens R, Gillerot $Y$, Heron D, Heron B, Benzacken B, Lacombe D, Brunner $H$, Bitoun P. Blepharophimosis-mental retardation (BMR) syndromes: a proposed clinical classification of the so-called Ohdo syndrome, and delineation of two new BMR syndromes, one X-linked and one autosomal recessive. Am J Med Genet $A$ 2006:140:1285-96.

6 Briscioli V, Manoukian S, Selicorni A, Livini E, Lalatta F. Kaufman oculocerebrofacial syndrome in a girl of 15 years. Am J Med Genet 1995:58:21-3.

7 Li H, Durbin R. Fast and accurate short read alignment with Burrows-Wheeler Transform. Bioinformatics 2009;25:1754-60

8 McKenna A, Hanna M, Banks E, Sivachenko A, Cibulskis K, Kernytsky A, Garimella K, Altshuler D, Gabriel S, Daly M, DePristo MA. The Genome Analysis Toolkit: a MapReduce framework for analyzing next-generation DNA sequencing data. Genome Res 2010;20:1297-303.

9 DePristo M, Banks E, Poplin R, Garimella KV, Maguire JR, Hartl C, Philippakis AA, del Angel G, Rivas MA, Hanna M, McKenna A, Fennell TJ, Kernytsky AM, Sivachenko AY, Cibulskis K, Gabriel SB, Altshuler D, Daly MJ. A framework for variation discovery and genotyping using next-generation DNA sequencing data. Nat Genet 2011:43:491-8

10 Cingolani P, Platts A, Coon M, Nguyen T, Wang L, Land SJ, Lu X, Ruden DM. A program for annotating and predicting the effects of single nucleotide polymorphisms, SnpEff: SNPs in the genome of Drosophila melanogaster strain w1118; iso-2; iso-3. Fly 2012;6:80-92.

11 Gong TW, Huang L, Warner SJ, Lomax MI. Characterization of the human UBE3B gene: structure, expression, evolution, and alternative splicing. Genomics 2003:82:143-52.

12 Basel-Vanagaite L, Dallapiccola B, Ramirez-Solis R, Segref A, Thiele H, Edwards A, Arends MJ, Miró X, White JK, Désir J, Abramowicz M, Dentici ML, Lepri F, Hofmann K, Har-Zahav A, Ryder E, Karp NA, Estabel J, Gerdin AK, Podrini C, Ingham NJ, Altmüller J, Nürnberg $G$, Frommolt $P$, Abdelhak $S$, Pasmanik-Chor $M$, Konen O, Kelley RI, Shohat M, Nürnberg P, Flint J, Steel KP, Hoppe T, Kubisch C, Adams DJ, Borck G. Deficiency for the ubiquitin ligase UBE3B in a blepharophimosis-ptosis-intellectual-disability syndrome. Am J Hum Genet 2012;91:998-1010

13 Hicke L. Protein regulation by monoubiquitin. Nat Rev Mol Cell Biol 2001;2:195-201. 
14 Jackson PK. An introduction to posttranslational control and ubiquitination. In: Epstein CJ, Erikson RP, Wynshaw-Boris A, eds. Inborn errors of development. Oxford: Oxford University Press, 2008:1148-60.

15 Schubert U, Anton LC, Gibbs J, Norbury CC, Yewdell JW, Bennink JR. Rapid degradation of a large fraction of newly synthesized proteins by proteasomes. Nature 2000;404:770-4.

16 Pickart CM. Back to the future with ubiquitin. Cell 2004;116:181-90.

17 Scarafia LE, Winter A, Swinney DC. Quantitative expression analysis of the cellular specificity of HECT-domain ubiquitin E3 ligases. Physiol Genomics 2000;4:147-53.

18 Kishino T, Lalande M, Wagstaff J. UBE3A/E6-AP mutations cause Angelman syndrome. Nat Genet 1997;15:70-3.

19 Matsuura T, Sutcliffe JS, Fang P, Galjaard R-J, Jiang Y, Benton CS, Rommens JM et al. De novo truncating mutations in E6-AP ubiquitin-protein ligase gene (UBE3A) in Angelman syndrome. Nat Genet 1997;15:74-7.

20 Crossey PA, Richards FM, Foster K, Green JS, Prowse A, Latif F, Lerman MI, Zbar B, Affara NA, Ferguson-Smith MA, Maher ER. Identification of intragenic mutations in the von Hippel-Lindau disease tumor-suppressor gene and correlation with disease phenotype. Hum Mol Genet 1994;3:1303-8.

21 Kitada T, Asakawa S, Hattori N, Matsumine H, Yamamura Y, Minoshima S, Yokochi M, Mizuno Y, Shimizu N. Mutations in the parkin gene cause autosomal recessive juvenile parkinsonism. Nature 1998;392:605-8.

22 Huber C, Dias-Santagata D, Glaser A, O'Sullivan J, Brauner R, Wu K, Xu X, Pearce K, Wang R, Uzielli ML, Dagoneau N, Chemaitilly W, Superti-Furga A, Dos Santos $H$, Mégarbané $A$, Morin $G$, Gillessen-Kaesbach $G$, Hennekam R, Van der Burgt I, Black GC, Clayton PE, Read A, Le Merrer M, Scambler PJ, Munnich A Pan ZQ, Winter R, Cormier-Daire V. Identification of mutations in CUL7 in 3-M syndrome. Nat Genet 2005;37:1119-24.

23 Zenker M, Mayerle J, Lerch MM, Tagariello A, Zerres K, Durie PR, Beier M, Hulskamp G, Guzman C, Rehder H. Deficiency of UBR1, a ubiquitin ligase of the $\mathrm{N}$-end rule pathway, causes pancreatic dysfunction, malformations and mental retardation (Johanson-Blizzard syndrome). Nat Genet 2005;37:1345-50.
24 Nagamine K, Peterson P, Scott HS, Kudoh J, Minoshima S, Heino M, Krohn KJ, Lalioti MD, Mullis PE, Antonarakis SE, Kawasaki K, Asakawa S, Ito F, Shimizu N. Positional cloning of the APECED gene. Nat Genet 1997;17:393-8.

25 Martinelli S, De Luca A, Stellacci E, Rossi C, Checquolo S, Lepri F, Caputo V, Silvano $M$, Buscherini $F$, Consoli F, Ferrara $G$, Digilio MC, Cavaliere ML, van Hagen JM, Zampino G, van der Burgt I, Ferrero GB, Mazzanti L, Screpanti I, Yntema HG, Nillesen WM, Savarirayan R, Zenker M, Dallapiccola B, Gelb BD, Tartaglia M. Heterozygous germline mutations in the CBL tumor-suppressor gene cause a Noonan syndrome-like phenotype. Am J Hum Genet 2010;87:250-7.

26 Niemeyer CM, Kang MW, Shin DH, Furlan I, Erlacher M, Bunin NJ, Bunda S, Finklestein JZ, Sakamoto KM, Gorr TA, Mehta P, Schmid I, Kropshofer G, Corbacioglu S, Lang PJ, Klein C, Schlegel PG, Heinzmann A, Schneider M, Starý J, van den Heuvel-Eibrink MM, Hasle H, Locatelli F, Sakai D, Archambeault S, Chen L, Russell RC, Sybingco SS, Ohh M, Braun BS, Flotho C, Loh ML. Germline CBL mutations cause developmental abnormalities and predispose to juvenile myelomonocytic leukemia. Nat Genet 2010;42:794-800.

27 Perez B, Mechinaud F, Galambrun C, Ben Romdhane N, Isidor B, Philip N, Derain-Court J, Cassinat B, Lachenaud J, Kaltenbach S, Salmon A, Désiréé C, Pereira S, Menot ML, Royer N, Fenneteau O, Baruchel A, Chomienne C, Verloes A, Cavé $\mathrm{H}$. Germline mutations of the CBL gene define a new genetic syndrome with predisposition to juvenile myelomonocytic leukaemia. J Med Genet 2010;47:686-91.

28 Johnson JM, Moonis G, Green GE, Carmody R, Burbank HN. Syndromes of the first and second branchial arches, part 1: embryology and characteristic defects. Am J Neuroradiol 2011;32:14-19.

29 Gorlin RJ. Branchial arch and oro-acral disorders. In: Gorlin RJ, Hennekam RCM, eds. Syndromes of the head and neck. Oxford: Oxford University Press, 2001:790-849.

30 Passos-Bueno MR, Ornelas CC, Fanganiello RD. Syndromes of the first and second pharyngeal arches: a review. Am J Med Genet A 2009;194A:1853-9. 